\title{
A trama da memória: sobre Ana Miranda, Adriana Varejão e Tatiana Salem Levy
}

Antonio Maura ${ }^{1}$

A memória nos forma tanto como indivíduos quanto como coletividade. Toda obra artística ou literária recorre a ela iniludivelmente. Não é por acaso que os clássicos a situavam na origem da criação: as Musas, tenham sido uma ou múltiplas, eram filhas de Mnemósine, isto é, da memória. O ser humano trabalha com ela para elaborar a história e para iluminá-la, articulando o passado, como já dizia Walter Benjamin, "não significando reconhecê-lo como tal ou como realmente o foi. Significa apoderar-se de uma recordação que relampeja no instante de um perigo" (Benjamin, 2008, p. 306). Recuperar a recordação que brilha um pouco antes de desaparecer, reinventá-la ou buscar seu significado é a tarefa do artista ou do intelectual. Neste artigo, eu gostaria de mostrar, como exemplos, alguns procedimentos literários e artísticos que lidam especificamente com a memória, com o passado e seus vestígios, para construir um espaço de compreensão e de gênese, pois toda obra artística, observada em seu conjunto, é um âmbito cerrado com suas coordenadas e limites, que devem servir também como ponto de referência. A arte é mensagem e memória, e não se sabe o que está antes, se a mensagem da memória ou a memória da mensagem. “O passado - dizia Benjamin no mesmo trabalho - comporta um índice secreto pelo qual se leva à redenção" (Benjamin, 2008, p. 307). E a redenção supõe algo mais que uma intelecção ou um conhecimento, é algo que nos implica de forma integral, que nos justifica ou que nos anula, que dá sentido ou arruína toda uma existência, quer seja a de um homem ou a de um povo.

É o passado e sua redenção que servem de temática para uma novela como A chave de casa (2010), ${ }^{2}$ da escritora brasileira Tatiana Salem Levy. Nessa obra se recupera a velha tradição judia de guardar as chaves de casa antes de partir para o exílio. Na Espanha, na década de 1980 e início de 1990, houve uma repercussão simbólica desse hábito, pois, quando foram devolvidas as antigas sinagogas a seu culto religioso originário,

\footnotetext{
${ }^{1}$ Doutor em filologia românica e assessor literário da Fundação Cultural Hispano-Brasileira, Madrid, Comunidade Autónoma de Madrid, Espanha. E-mail: amauraba@gmail.com

${ }^{2}$ Traduzida para o espanhol de forma equivocada como La llave de Esmirna.
} 
suas fechaduras foram refeitas para que as portas pudessem ser abertas com as mesmas velhas chaves que os descendentes dos rabinos haviam conservado, guardando-as durante todo o exílio. No romance de Levy, a protagonista leva consigo a chave da casa familiar perdida, e é esse objeto que dá consistência à narração, na qual as palavras não pretendem explicar um símbolo - a chave -, mas surgem a partir dele: o discurso é um caminho que há de servir para dar sentido ao mundo.

No entanto, as palavras ainda me escapam, a história ainda não existe. Enquanto os músculos pesam e permanecem, o sentido se esvai. Quem sabe, aos poucos, quando conseguir dar os primeiros passos, quando conseguir me libertar do fardo, não consiga também dar nome às coisas? E por isso, só por isso escrevo (Levy, 2010, p. 10).

A escritura é algo mais que um simples relato que possa ser contado melhor ou pior, é uma missão, um destino que acabará por salvar ou condenar sua narradora e protagonista - e com ela o leitor. $\mathrm{O}$ sentido da história se recupera com um objeto simbólico, que está além da linguagem e das recordações e, como recordava Benjamin, leva à redenção.

Tatiana, nascida em Lisboa em 1979, retoma essa temática em seu segundo romance, Dois rios (2011). Nessa história, graças ao amor por uma mesma mulher - cujo nome, Marie-Ange, é um símbolo -, dois irmãos gêmeos de ambos os sexos podem reencontrar-se em plenitude, semelhante ao mar, para o qual confluem os rios. Trata-se de uma história a duas vozes, cujo ponto de encontro é o anjo: será o anjo da história ao qual se referia Benjamin e cujo ícone pintou Klee?

Bem diferente é o planejamento narrativo da escritora Ana Miranda (Ceará, 1951), cuja trajetória se iniciou com seu romance histórico Boca do Inferno (1989). Ainda que na obra dessa escritora se intercalem o conto, a poesia e o relato infantil, algo que também sucede com Salem Levy, existe um discurso continuado, um tipo de trama linguística, com a qual se pretende incorporar o passado. Se em Boca do Inferno tratava-se de dar vida ao poeta Gregório de Matos e à Bahia de sua época, nas narrações históricas seguintes, exploram-se diferentes paisagens do passado com o fim de entender o presente. Seu romance A última quimera, de 1995, centra-se na figura de Augusto dos Anjos e no Brasil do final do século XIX e início do século XX. O narrador é amigo pessoal do poeta, por isso conta os momentos mais significativos de sua vida, além de descrever a cidade do Rio de Janeiro, seus distintos encontros intelectuais e humanos - especialmente com Olavo Bilac - com uma 
prosa cadenciosa, harmônica e elegante, como condiz a um membro da boa sociedade carioca. Essa proximidade dos fatos e dos personagens históricos na voz do narrador devolve aos leitores, de algum modo, a forma decadente e desinibida da sociedade brasileira daquele tempo.

Já em 2002, Miranda publicou Dias \& Dias, no qual aborda a figura do poeta Gonçalves Dias ao mesmo tempo que oferece uma visão do século XIX brasileiro, cujas complexidades intelectuais e literárias são também tratadas em seu último romance, Semíramis, publicado em 2014. Se Augusto dos Anjos foi um poeta maldito, falecido prematuramente aos 30 anos, por sua vez, Antônio Gonçalves Dias morreu com pouco mais de 40, durante seu regresso para o Brasil, depois de um período de estadia na Europa por motivo de saúde: o navio em que viajava, o Ville de Boulogne, naufragou nos bancos de Atins, pouco antes de chegar a São Luís, capital do Maranhão. O poeta, já muito doente, foi o único passageiro que não conseguiu se salvar. Essa morte tão romântica de um dos poetas mais românticos do Brasil é glosada ao longo do romance por uma mulher que espera no cais de São Luís pela chegada do poeta. Esse tempo de espera é também o da duração narrativa do romance, no qual uma voz feminina vai contando as anedotas de uma vida cheia de dificuldades, mas também de momentos de plenitude. $\mathrm{O}$ discurso desse livro, inspirado nas cartas e nos diários do poeta, faz referência, continuamente, à fala daquela época. Ana Miranda considera muito importante a recuperação linguística de um tempo como forma de aproximação histórica. Em uma entrevista concedida à revista Quimera em dezembro de 2013, a escritora afirmava: "Vou à procura das fontes linguísticas para enriquecer a fala de meus personagens e que isso permita relacionar-me com a história literária" (Miranda, 2013, p. 51).

Com essa bagagem textual, a romancista cearense coloca-se diante de um passado, talvez não tão remoto, mas significativo, para a constituição de um país e de uma identidade nacional:

Tenho plena consciência de que estou penetrando nos mistérios daquilo que é o Brasil, não só através de minha visão pessoal, mas através de uma história literária que realmente existe. Em Dias $\mathcal{E}$ Dias descobri como se configurava o rosto do Brasil, tal como ocorreu pouco depois da Independência, em 1822, no período romântico, quando a literatura teve essa missão (Miranda, 2013, p. 51).

A reflexão sobre os textos literários, mais que a pura biografia, é, portanto, a forma de escrever que Ana Miranda foi elaborando ao longo 
de quase trinta anos de sua obra criativa. Buscar o "rosto do Brasil", como lembra na entrevista mencionada, é sem dúvida seu objetivo prioritário. Em outras narrativas, como em Desmundo ou Amrik, publicadas em 1996 e 1997, respectivamente, a autora trata do problema da imigração -no primeiro texto, a portuguesa e, no segundo, a libanesa -, já que supõe um dos aspectos mais enigmáticos e épicos da história do grande país americano.

Desmundo tem sua origem no século XVI e sua base é um episódio verídico que relata a chegada ao Brasil de um navio cheio de órfãs, enviadas do Velho Mundo para casar com os colonos - os quais, em sua maioria, viviam em concubinato com indígenas -, para que pudessem formar na colônia uma população portuguesa, de raça branca. A narrativa tem voz feminina, a de Oribela, uma mocinha órfã que viaja no navio e descobre um novo mundo cheio de contradições: o português decadente, representado pelo homem a quem é destinada, Francisco de Albuquerque, que se opõe ao de Temericô, a criada indígena que cuida dela e acaba tornando-se sua confidente. Graças a Temericô, a protagonista e narradora conhece a língua tupi e a riqueza medicinal e alimentícia das plantas e frutos americanos, além da luxuriante beleza de seus lugares e de seu mistério:

As plantas não têm alma, as mulheres não têm barba, os passarinhos não têm leite, abá supé-pe oro-iko-né? Muitas mais coisas ensinou a natural, de sua fala, kûarasy sem'îanondé, xe mombak-i, que dizia. Antes do nascer do sol ele me acordou, e xe rausu'-poir-eym-i, que dizia. Não deixou de me amar e outra coisa, $a-\hat{\imath}-t y^{\prime}$-rung soó, que dizia (Miranda, 2006, p. 127).

$\mathrm{O}$ enfrentamento entre o falsamente civilizado e o enganosamente selvagem, entre o poder sem grandeza dos colonos portugueses e a grandeza sem poder dos indígenas, conduz a protagonista a prevenir-se da inversão de valores no continente americano, onde, por um lado, prima a injustiça, a hipocrisia e a mentira, enquanto, por outro, a harmonia, a nobreza e a verdade são vilipendiadas e escravizadas. Portanto, não se trata de um mundo novo, mas, sim, de um "desmundo", pois foi nisso que o homem branco o converteu.

Amrik é a palavra com que os árabes denominam a América. O romance que leva esse título é a história de uma emigrante libanesa que, depois de muitas atribulações, chega a São Paulo dos últimos anos do século XIX ou início do XX. Ainda que a narradora tenha nome e família, o 
verdadeiro protagonista do relato é a própria linguagem. Lemos como se contemplássemos os bailes e as vestimentas ou cheirássemos os diferentes pratos que sabe preparar Aminta, sua pretendida narradora-protagonista, ou sentíssemos a sensualidade que impregna o ar e o espaço que pisam seus pés de dançarina. O romance Amrik é poesia construída com sábias palavras como a de Omar Khayyam, ou com histórias fantásticas como as das Mil e uma noites. A viagem para qual nos convida esse livro é a um dos mundos mais especiais e recônditos: o das comunidades árabes do Brasil. Nos séculos XX e XXI, dois romancistas de fortes raízes libanesas - Raduan Nassar e Milton Hatoum - descreveram o mundo dos libaneses, cristãos ou muçulmanos em terras brasileiras. O romance de Miranda aporta uma voz feminina, uma sensualidade e um sabor que não desmerecem os relatos desses dois autores, um deles, Milton, bom amigo da autora cearense.

Yuxin, publicado em 2009, é, possivelmente, um somatório desses dois livros anteriores, em que a linguagem adquiriu tanta importância que o argumento rende-se à voz feminina narrando com sua sinuosa ondulação, mais atenta a inquietudes e desejos que ao relato dos fatos. Yuxin é o nome que recebe a alma, o espírito, na língua falada pelos indígenas brasileiros do estado do Acre. E essas almas vagam pela selva dotando de vida os seres da floresta, sejam animados ou inanimados. A história de fundo dessa narrativa é o final de um povo, já que sua protagonista, Yuxin, chora primeiro pelo desaparecimento do pai de seus filhos e, logo, por toda sua família. Para onde foram? As almas os levaram? Perderam-se nos labirintos da floresta? Foram assassinados por caboclos, pelos brancos que desbravam as terras ou devorados pelas onças? Yuxin é o canto de uma mulher pelo desaparecimento de uma cultura, de uma forma de vida, de um mundo...

Xumani sempre voltou... há de voltar... amanhã de amanhã de amanhã de amanhã... kreô kreô kreô kreô... vi as almas de nossa gente morta, nossas almas... dançamos... assim foi... bordar... awa bena, borboletas deitadas de asas abertas, assim, assim, aqui asa de borboleta... aquele bordado ali é borboleta deitada... nós sonhamos, outra vez sonhamos, outra vez dormimos, agora muito longe andamos, nossas almas... ali dormimos, deitados, as almas nos largaram, saíram... andaram longe... as almas se preparam para levar nossa alma... almas pelejam entre si... almas se flecham entre si... almas se espancam entre si... almas se furam entre si... eu vi... as almas se amarram os pescoços, as almas se afogam rio adentro, eu vi... as almas sobem e caem, vi... 
as almas copulam, vi... as almas morrem, vi... as almas choram, vi... as almas voltam para nossos corpos, acordamos, falamos dormindo... são as vozes das almas... vi... as almas nos agarram a alma enquanto dormimos, assim não podemos falar, não podemos gritar, mas gritamos, falamos dormindo, tudo são as almas, elas nos levam para a lonjura, elas mandam nos buscar, elas levam os nossos, elas mandam em tudo, fazem tudo o que acontece, as almas mandam em nós... tudo, mandam em tudo as almas... titiri titiri titiri titiri wẽ... hutu, hutu, hutu, hutu... titiri titiri titiri titiri wẽ... idiki, idiki, idiki... eh, eh, eh, eh... idiki, idiki, idiki... idiki, idiki, idiki... brẽ brẽ brẽ brẽ... hutu, hutu, hutu, hutu... hutu, hutu, hutu, hutu... idiki, idiki, idiki... eh, eh, eh, eh... titiri titiri titiri titiri wẽ... hutu, hutu, hutu, hutu... eh, eh, eh, eh, idiki, idiki, idiki... eh, eh, eh, eh, kwéék! hutu, hutu, hutu, hutu... brẽ brẽ brẽ brẽ... kreõ kreõ kreõ kreõ... titiri titiri titiri titiri wẽ... hutu, hutu, hutu, hutu... (Miranda, 2009, p. 332).

O romance acaba com este parágrafo enigmático que mais parece uma prece. Mais que um relato, trata-se de um poema épico que teria sido do gosto de Gonçalves Dias, quem, como já se mencionou, foi o tema de uma de suas obras mais emblemáticas. Mas também desenvolve o tratamento da linguagem que se iniciou em Desmundo. Há, portanto, uma continuidade indiscutível tanto temática quanto linguística na narrativa de Ana Miranda. Talvez mais que em qualquer outro romance, em Yuxin, a escritora cearense deixou voar sua imaginação e permitiu-se uma liberdade poética e léxica que, no Brasil, somente se viu em alguns relatos de Guimarães Rosa, como em Meu tio o iauaretê.

O crítico, poeta e também acadêmico Marco Lucchesi escreve sobre Yuxin:

Yuxin é um romance de grande biodiversidade. Nenhum outro revelou com tamanha materialidade semântica, sintética, sonora, vozes de animais. $\mathrm{O}$ rumor dos rios. Das plantas. E do silêncio. Mas dentro de uma chave poética que aprofunda a sensibilidade da narradora-personagem, em cujo mundo interior repercutem tais vozes (Lucchesi, 2009, contracapa).

O romance vem acompanhado de um $\mathrm{CD}$ produzido pela irmã da escritora, Marlui Miranda, em que se recitam parágrafos do livro e se reproduzem canções indígenas. A obra adquire assim uma profundidade sonora, uma nova dimensão dramática e lírica condizente 
com uma artista integral, que ilustra seus livros com seus próprios desenhos e com seus versos de poeta ativa.

Semíramis, publicado em 2014, é a última entrega dessa reflexão sobre o passado literário de seu país. Trata-se de relembrar a figura de José de Alencar e de seu século, que já foi tratado em seus romances Dias $\mathcal{E}$ Dias e A última quimera. Novamente, é uma voz feminina que conta a historia. São duas mulheres: uma é Irina, que narra o argumento a partir das cartas de sua irmã, Semíramis, que lhe explica o que acontece no Rio de Janeiro. Assim, duas realidades se contrapõem: a da província e a da Corte e, como pano de fundo, está a figura de José de Alencar. Escolher um personagem feminino como narrador já é uma constante na obra de Ana Miranda desde seu romance Desmundo. Se sempre é complexo afrontar a história de uma época a partir de uma única voz, e que esta seja uma voz feminina, acrescenta-se ao argumento uma nova perspectiva, porque a mulher, naqueles tempos narrados, era considerada um ser menor de idade, incapaz para todos os efeitos. Porém, justamente por isso, a escolha foi certeira, pois somente somos capazes de captar a época que nos tocou viver a partir de nossa microhistória. E o fato de a narradora ser uma mulher dota a obra de uma voz anônima que, aparentemente, não transcende, porém é significativa, porque, sendo alheia às ambições e interesses masculinos, transborda sensibilidade e conhecimento daquilo que é mais elementar e necessário, como o são a culinária, as plantas, a paisagem, o amor, os comentários da gente dos povoados, sua forma de vida etc. Tudo isso fica maravilhosamente plasmado na última obra de Ana Miranda, que, na entrevista anteriormente mencionada, afirmou:

A intertextualidade é fundamental para a elaboração de meus livros porque sou uma escritora que trabalha com a reconstrução de linguagens perdidas, não de tempos perdidos como diria Marguerite Yourcenar, mas de linguagens que se perderam no tempo. Para viajar ao passado, o caminho passa pela linguagem, pela leitura dos textos da época. Viajo com a linguagem, com a imaginação através das palavras que vão dando referências da época e me permitem reconstruir um tempo de uma forma extraordinária e fantástica. A linguagem tem esse poder de aprisionar o tempo e revelá-lo (Miranda, 2013, p. 52).

Trabalhar com a linguagem de diferentes épocas para torná-las compreensíveis é o que faz, a partir de um aspecto plástico, Adriana 
Varejão (Rio, 1964). Em seu caso não se trata de palavras, mas, sim, de imagens. De fato, à temática descrita por Ana Miranda no romance Desmundo, a artista carioca parece ter oferecido uma réplica plástica. Essa confrontação entre o mundo civilizado português e o selvagem indígena em tempos coloniais encontra-se em obras como Propostas para uma catequese, de 1993, ou nas três variantes de Figura de convite, de 1997, 1998 e 2005, respectivamente. Um olhar crítico acerca da colonização também foi apresentado em peças como Filho bastardo, em sua dupla variante de 1992 e 1995, assim como nas obras Lingua como padrão sinuoso, de 1998, ou Ruínas de charque, de 2002, ainda que de um modo menos explícito. A temática indígena tratada em Yuxin pode ser encontrada também em obras como Em segredo, de 2003, ou Contingente Yanomani, do mesmo ano. Por outra parte, o interesse que Ana Miranda mostra em seus livros por alimentos, plantas e frutos, que se traduz em arte culinária, oferece um paralelo com as cerâmicas e pratos de Adriana Varejão, tais como Pérola imperfeita, Mãe D'água e Sereias bêbadas, obras de 2009, e Prato com mariscos, de 2011.

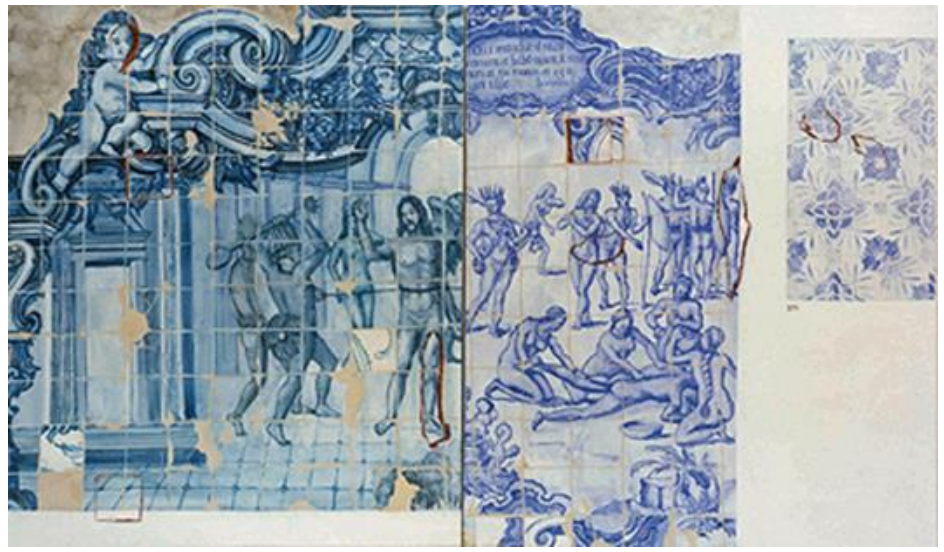

Figura 1 - Propostas para uma catequese: morte e esquartejamento (1993), de Adriana Varejão. Fonte: Enciclopédia Itaú Cultural. ${ }^{3}$

Na peça de 1993, Propostas para uma catequese: morte $e$ esquartejamento (Figura 1), o significado global da obra surge das

\footnotetext{
${ }^{3}$ Disponível em: <https://goo.gl/w5Qtyu>.
} 
múltiplas referências com as quais foi construída a imagem. Varejão afirma, citando Severo Sarduy: "o meu trabalho é como uma câmara de ecos". Inicialmente, damo-nos conta de que essa peça imita azulejos da tradição portuguesa. Em seu centro, encontramos a figura de Cristo, que assiste a uma cerimônia de antropofagia da qual é também o protagonista. As imagens de canibalismo, não a de Cristo, evidentemente, foram tomadas das ilustrações do livro Américae, de Theodore de Bry, do século XVI. Cristo está a ponto de receber o golpe fatal que o levará a ser devorado pelos indígenas, como se pode ver do lado direito da peça. Sobre a cena há um rótulo em latim: Qui manducat mean carnem e bibit meum sanguinem ia me manet, et ego in illo (Quem coma da minha carne e beba do meu sangue estará em mim e eu nele). É uma referência a uma citação evangélica que alude ao sacramento da comunhão, junto a uma ilustração explícita do que se diz simbolicamente. O que parece uma simples ironia provocadora é apenas uma justificativa do comportamento indígena diante do inimigo ou do mal, que, como explicava Lévi-Strauss, incorpora-o ao grupo em vez de expulsá-lo, como no Ocidente: antropofagia versus antropoemética (do grego emein, vomitar). A própria artista, em entrevista concedida a Felipe Scovino, em dezembro de 2008, comenta que o significado da obra "eram os índios ensinando a antropofagia aos portugueses, dando-lhes uma lição de catequese, uma contracatequese" (Varejão apud Scovino, 2009, p. 207-231).

A cena é rematada por uma orla, na qual se pode ver várias figuras de anjos, tomadas dos mosaicos dos altares barrocos brasileiros e dos mosteiros portugueses. A tradição colonial junta-se às ilustrações do gravador holandês para compor uma imagem nova, atual, permitindo uma releitura crítica da história.

Com semelhantes apresentações, a obra Filho bastardo, de 1992 e 1995 (figuras 2 e 3), mostra a imagem da colonização portuguesa em sua dupla variante: por um lado, o poder econômico e ideológico; e por outro, a exploração, em todos seus aspectos, das denominadas raças inferiores e primitivas. 


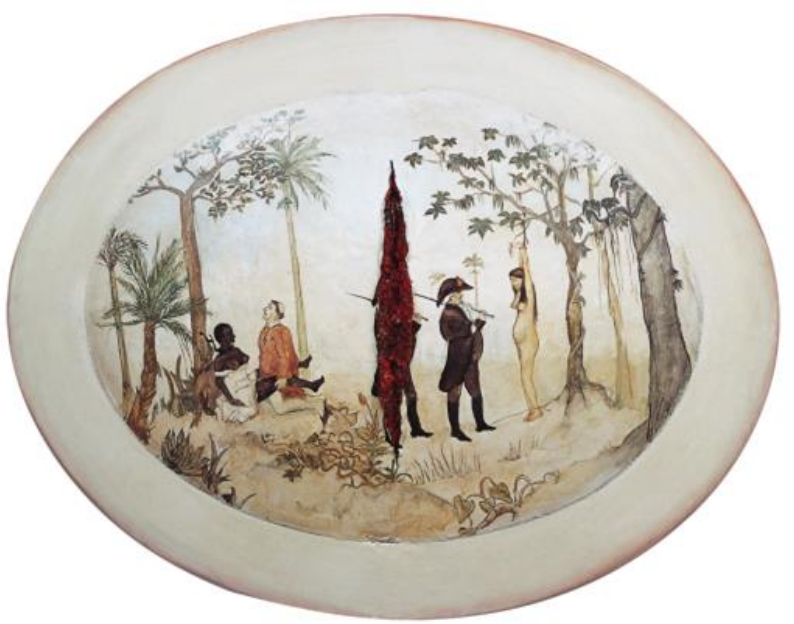

Figura 2 - Filho bastardo (1992), de Adriana Varejão. Fonte: Enciclopédia Itaú Cultural. ${ }^{4}$

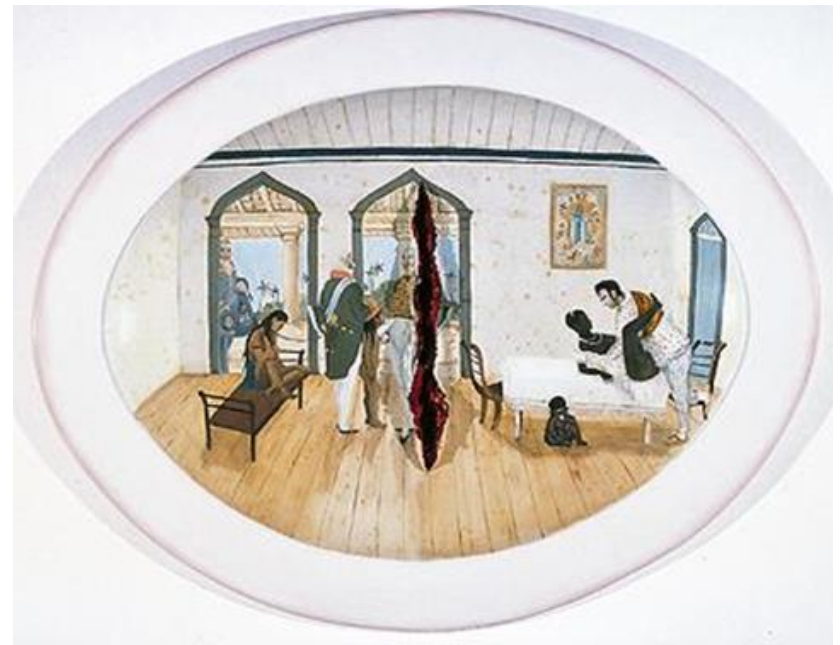

Figura 3 - Filho bastardo II, Cena de interior (1995), de Adriana Varejão. Fonte: Enciclopédia Itaú Cultural. ${ }^{5}$

\footnotetext{
${ }^{4}$ Disponível em: <http://enciclopedia.itaucultural.org.br/pessoa17507/adriana-varejao〉.
} 
As imagens são inspiradas nas gravuras da obra Voyage pittoresque et historique au Brésil, de Jean-Baptiste Debret, obra editada na França, em 1834. Trata-se de uma ilustração costumbrista, como era próprio da decoração das casas burguesas do século XIX: em meio de um agradável arvoredo, mostra-se fatos habituais, que naquele tempo não eram descritos, mas aconteciam. A elegante forma oval do quadro e sua paisagem bucólica contrapõem-se aos fatos revelados, enquanto uma mancha sangrenta atravessa a imagem, cortando-a como uma ferida aberta.

Na entrevista mencionada, de dezembro de 2008, a artista carioca afirmava: "A questão do trabalho do filho bastardo era a paródia, era o uso da obra de Debret, porque ele foi o pintor da história oficial. A minha obra dizia assim: 'Debret, tem uma história que você não contou, que é essa...' Mas não há ironia, eu queria me colocar como agente da história" (Varejão apud Scovino, 2009, p. 218).

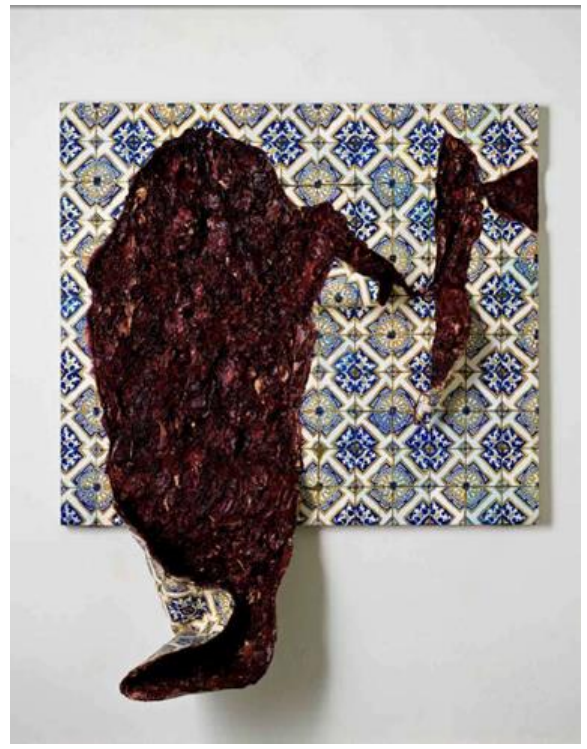

Figura 4 - Língua como padrão sinuoso (1998), de Adriana Varejão. Fonte: Enciclopédia Itaú Cultural. ${ }^{6}$

\footnotetext{
${ }^{5}$ Disponível em: <http://enciclopedia.itaucultural.org.br/pessoa17507/adriana-varejao〉.

${ }^{6}$ Disponível em: <http://enciclopedia.itaucultural.org.br/pessoa17507/adriana-varejao〉.
} 
Na obra de 1998, Língua como padrão sinuoso (figura 4), uma mancha se desprende de uma parede de azulejos, formosa e decorativa, e pode ser considerada como um símbolo não apenas da história do Brasil, mas de toda a América, de norte a sul, onde se implantou a civilização ocidental a sangue e fogo. Existe, sem dúvida, uma referência à iconografia da carne tratada por Rembrandt ou Goya, em Soutine ou Bacon, porém o significado aqui é diferente, pois sugere uma ferida aberta nas entranhas decorativas e amáveis da nossa civilização. Para terminar, veja-se a imagem da obra Em segredo, de 2003, onde se mostra a destruição de um povo e de uma cultura, como a indígena do Brasil, tal como se narra, poeticamente, em Yuxin, de Ana Miranda. Nesse caso é evidente a coincidência de ambas as perspectivas.

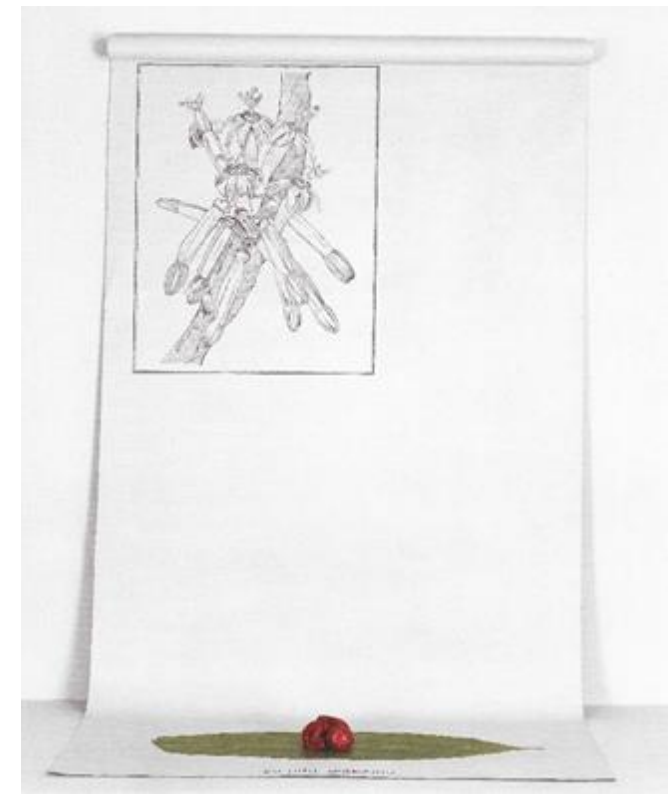

Figura 5 - Em segredo (2003), de Adriana Varejão.

Fonte: Schwarcz e Varejão (2014). 


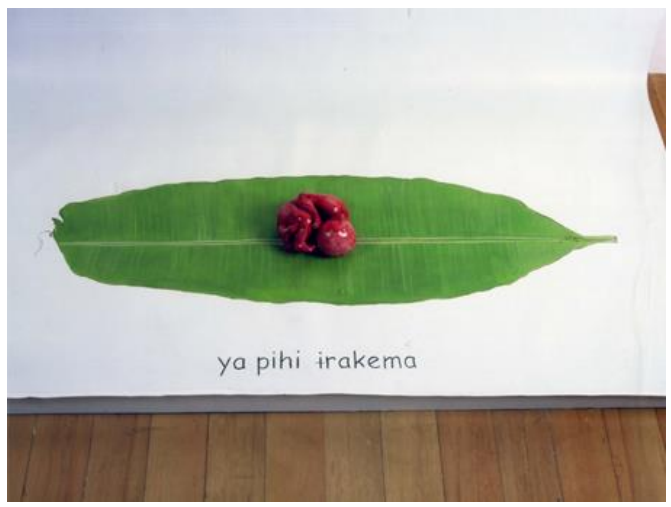

Figura 6 - Em segredo, detalhe (2003), de Adriana Varejão. Fonte: Secretaria de Cultura do Rio de Janeiro. ${ }^{7}$

Se no romance de Miranda é uma voz feminina a que canta a beleza e a riqueza da selva e a destruição de todo um povo e de uma visão do mundo, o mesmo acontece com uma tela de Varejão, pintada a óleo, com uma escultura de resina. A obra imita um pergaminho desfraldado com uma única figura de planta na parte superior, tomada de um antigo livro de botânica. Na parte inferior, um feto repousa sobre uma folha de bananeira, junto a qual se lê a frase Ya pihi irakema, que significa "estou contaminado", em língua Yanomami, segundo informa a artista.

Na parte superior, à esquerda, vê-se uma ilustração possivelmente inspirada na obra de frei Cristovão de Lisboa, do século XVII, ou nas notas da expedição de Alexandre Rodrigues Ferreira, do século XVIII. Na parte inferior, encontra-se uma imagem de forte impacto emocional, em que a morte ladeia o nascimento. Abaixo, uma realidade sangrenta e, acima, a imagem da floresta representada por uma reprodução botânica de séculos pretéritos. A artista parece querer dizer que a realidade é hoje uma cara irônica do que antes foi, um canto ferido, um anjo da história, como aquele do qual falava Walter Benjamin, que observa o passado com as asas desdobradas enquanto acumulam-se ruínas a seus pés.

Talvez essa seja a impressão que essas duas artistas querem passar: uma, da palavra, e a outra, da imagem. Elas veem o Brasil com olhos críticos e reconhecem em seu passado a grandeza e a mesquinharia que

${ }^{7}$ Disponível em: 〈http://goo.gl/sWvFRw〉. 
suporta toda civilização. Porém, suas histórias são de uma extrema beleza e força plástica. E a beleza sempre alenta a esperança. Confessava-me Ana Miranda que seu propósito era realizar uma obra com fundamento, que descobrisse o passado através da linguagem e o incorporasse a este presente tão frágil quanto instável; tão cheio de contradições quanto os séculos que o antecederam. Creio que é também esta a forma de ver a obra de Adriana Varejão. ${ }^{8} \mathrm{O}$ fato de oferecer sua visão como uma soma de referências indica a multiplicidade de linguagem de que somos constituídos e seus contraditórios significados. Finalmente, somos história e o que nos distingue é a forma pela qual a interpretamos, como elaboramos nossas lembranças e como construímos um relato coerente com a trama da memória.

\section{Referências}

BENJAMIN, Walter (2008). Sobre el concepto de Historia. Obras, libro I / vol. 2. Trad. Alfredo Brotons Muñoz. Madrid: Abada Editores.

LUCCHESI, Marco (2009). Contracapa. In: MIRANDA, Ana (2009). Yuxin (Alma). São Paulo: Companhia das Letras.

MIRANDA, Ana (1989). Boca do Inferno. São Paulo: Companhia das Letras.

MIRANDA, Ana (1995). A última quimera. São Paulo: Companhia das Letras.

MIRANDA, Ana (1997). Amrik. São Paulo: Companhia das Letras.

MIRANDA, Ana (2002). Dias \& Dias. São Paulo: Companhia das Letras.

MIRANDA, Ana (2006). Desmundo. São Paulo: Companhia das Letras.

MIRANDA, Ana (2009). Yuxin (Alma). São Paulo: Companhia das Letras.

MIRANDA, Ana (2013). "Somos prisioneros del tiempo y del lenguaje". Entrevista a Antonio Maura. Quimera: Revista de Literatura, Barcelona, n. 361, p. 50-54.

MIRANDA, Ana (2014). Semíramis. São Paulo: Companhia das Letras.

LEVY, Tatiana Salem (2010). A chave de casa. Rio de Janeiro: Record.

LEVY, Tatiana Salem (2011). Dois rios. Rio de Janeiro: Record.

\footnotetext{
${ }^{8}$ De fato, na entrevista citada, de dezembro de 2008, Varejão afirma: "Minha função é colocar perguntas para o trabalho, incitá-lo a novos questionamentos, e faço isso colocando elementos que dialoguem entre si, tentando fazer com que a obra seja o mais abrangente possível" (apud Scovino, 2009, p. 230.)
} 
SCHWARCZ, Lilia Moritz; VAREJÃO, Adriana (2014). Pérola imperfeita: a história e as histórias na obra de Adriana Varejão. São Paulo: Cobogó; Companhia das Letras.

SCOVINO, Felipe (2011). Arquivo contemporâneo. Rio de Janeiro: 7Letras.

Recebido em fevereiro de 2016.

Aprovado em julho de 2016.

\section{resumo/abstract/resumen}

\section{A trama da memória: sobre Ana Miranda, Adriana Varejão e Tatiana Salem Levy}

\section{Antonio Maura}

A arte, às vezes, é uma especial elaboração do passado. Não se trata de um passado real - ainda que adote os modos do romance histórico -, mas dos restos da memória e de seu tratamento plástico ou linguístico. Refiro-me a criadoras como as romancistas Tatiana Salem Levy (Lisboa, 1979) e Ana Miranda (Fortaleza, 1951), e a artista plástica Adriana Varejão (Rio de Janeiro, 1964). Em todas elas a memória recebe um tratamento novo. No caso destas artistas, não se pretende rememorar, mas recriar o tempo passado produzindo novos objetos, novos textos, que sirvam para interpretar a realidade, as lembranças, a possível realidade de uma época arcaica, remota, que unicamente a arte é capaz de desvendar.

Palavras-chave: memória, arte, Ana Miranda, Adriana Varejão, Tatiana Salem Levy.

\section{The weave of memory: Ana Miranda, Adriana Varejão and Tatiana Salem Levy}

\section{Antonio Maura}

Art is, at times, a re-elaboration of the past. It does not constitute a real past - even when it takes the form of the historical novel - but offers instead the vestiges of memory and its artistic or linguistic interpretation. I am referring here to the creative interpreters of memory such as the novelists Tatiana Salem-Levy (Lisbon, 1979) and Ana Miranda (Fortaleza, 1951), and the Brazilian artist Adriana Varejão (Rio de Janeiro, 1964). In all of them memory receives a new interpretation. In the work of these artists, the intention is not to remember but to recreate the past, producing 
new objects, new texts that may serve to interpret the memories, the possible reality of a remote, archaic time, which only art is capable of revealing.

Keywords: memory, art, Ana Miranda, Adriana Varejão, Tatiana Salem Levy.

\section{La urdimbre de la memoria: sobre Ana Miranda, Adriana Varejão y Tatiana Salem Levy}

\section{Antonio Maura}

El arte, a veces, es una elaboración especial del pasado. No se trata de un pasado real - a pesar de que adopte la forma de la novela histórica - , sino de los vestigios de la memoria y de su tratamiento plástico o lingüístico. Me refiero a creadoras como las novelistas Tatiana Salem-Levy (Lisboa, 1979) y Ana Miranda (Fortaleza, 1951), y también a la artista plástica Adriana Varejão (Río de Janeiro, 1964). En todas ellas la memoria recibe un tratamiento nuevo. En el caso de éstas artistas, no se pretende rememorar, sino de recrear el tiempo pasado produciendo nuevos objetos, nuevos textos, que sirvan para interpretar los recuerdos, la posible realidad de una época arcaica, remota, que sólo el arte es capaz de desvelar.

Palabras clave: memoria, arte, Ana Miranda, Adriana Varejão, Tatiana Salem Levy. 